\title{
Oxytalan Fibers in the Periodontium of Ascorbic Acid-Deficient Guinea Pigs
}

\author{
M. C. KANOUSE \\ The University of Michigan, School of Dentistry, Department of Periodontics, Ann Arbor, Michigan
}

\section{SYNOPSIS IN INTERLINGUA}

Fibras de Oxytalano in le Periodontio de Porcos de India a Carentia de Actdo Ascorbic.-Le function del fibras de oxytalano non es cognoscite. Per medio de technicas de tincturation histochimic, il ha essite constatate que fibras de oxytalano differe de fibras de collageno in lor structura chimic e in lor orientation. Le objectivo del presente investigation esseva clarificar le natura de iste fibras a base de un evaluation del responsa de fibras de oxytalano a un manco de acido ascorbic. Esseva constatate que le fibras de collageno in le membrana periodontal declinava in numeros con le crescente severitate del carentia de acido ascorbic durante que le fibras de oxytalano remaneva inalterate in lor numeros $\mathrm{e}$ in lor distribution.

The existence of oxytalan fibers in the periodontium of human beings and animals has been reported. ${ }^{1-8}$ The function of these fibers is unknown, but it has been suggested that they may have a suspensory function and possibly may be analogous in function to elastic tissue. ${ }^{4}$ By the use of histochemical stains, oxytalan fibers have been shown to differ from collagen fibers in chemical structure and in orientation.

The objective of this investigation was to study the possible differences between oxytalan and collagenous fibers by the use of ascorbic acid-deficient guinea pigs in which the collagen component of the periodontium had been reduced, thus providing an opportunity to evaluate the response of the oxytalan fibers to lack of ascorbic acid.

\section{Materials and Methods}

Twenty-four Hartley strain guinea pigs, 6 to 8 weeks old and weighing 180 to 280 $\mathrm{Gm}$., were allotted to six groups of 4 guinea pigs each and pair-fed with controls that were treated in an identical manner. They were all given ascorbic acid-free, semisynthetic diets of Reid and Briggs ${ }^{9}$ for the experimental period of 30 days. In addition, guinea pigs in groups $1,2,3,4$, and 5, respectively, were given interperitoneal injections of $1.25,0.8,0.6,0.4$, and $0.2 \mathrm{mg}$. of

This investigation was supported by U.S. Public Health Service Research Grant 1-S21-FR-05321-01, from the General Research Support Branch, Division of Research Facilities and Resources, National Institutes of Health, Bethesda, Md.

Received for publication January 12, 1965. ascorbic acid per $100 \mathrm{Gm}$. of body weight Those in the sixth group received no ascorbic acid. Levels of ascorbic acid were determined at least once per week by the method of Roe and Keuther. ${ }^{10}$ At the end of 30 days, the guinea pigs were sacrificed and their jaws were fixed in 10 per cent neutral formalin, decalcified in 3 per cent hydrochloric acid, and sectioned at $8 \mu$. To demonstrate the fibers, the tissues were stained according to the peracetic-elastase sequence, the peracetic-glucuronidase sequence, the aldehyde fuchsin sequence, or the peraceticaldehyde fuchsin sequence. ${ }^{1,4,5}$ Because the periodontal membrane showed no elastic fibers when stained with the peraceticglucuronidase sequence or with the aldehyde fuchsin stain, the use of a differential stain to show only oxytalan fibers was deemed unnecessary.

The number of oxytalan fibers was evaluated by counting the number of fibers passing between two points, 0.1 of a millimeter apart. These counts were made in the incisor region at three locations 0.1 millimeter apart in an apical direction from the epithelial attachment (Fig. 1, Area I) and, beginning at the level of the alveolar crest, at three locations 0.1 millimeter apart in the central portion of the periodontal membrane (Fig. 1, Area II).

\section{Results}

Normal ascorbic acid level (Fig. 2).-At an ascorbic acid intake level of $1.25 \mathrm{mg}$. 


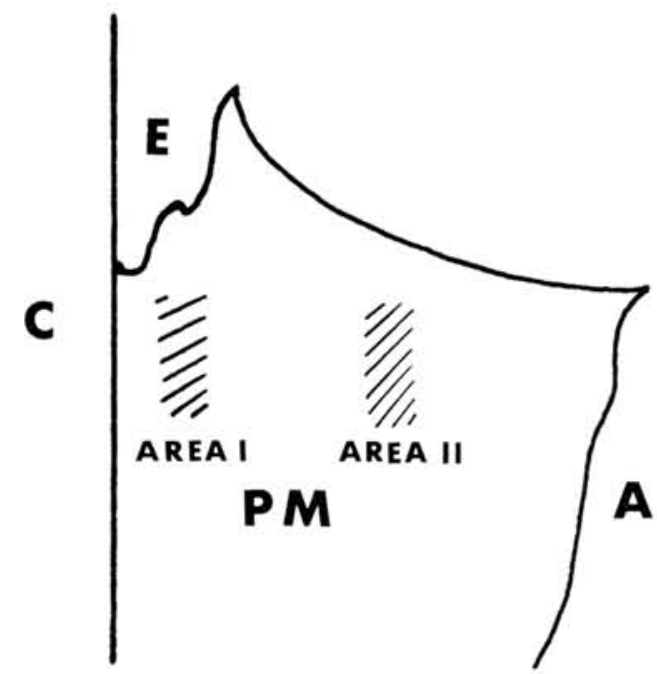

FIG. 1.- Schematic representation of the periodontal membrane of the maxillary incisor region showing the location of Areas I and II. A = alveolar bone, $\mathrm{C}=$ cementum, $\mathrm{E}=$ epithelial attachment, $\mathrm{PM}=$ periodontal membrane.

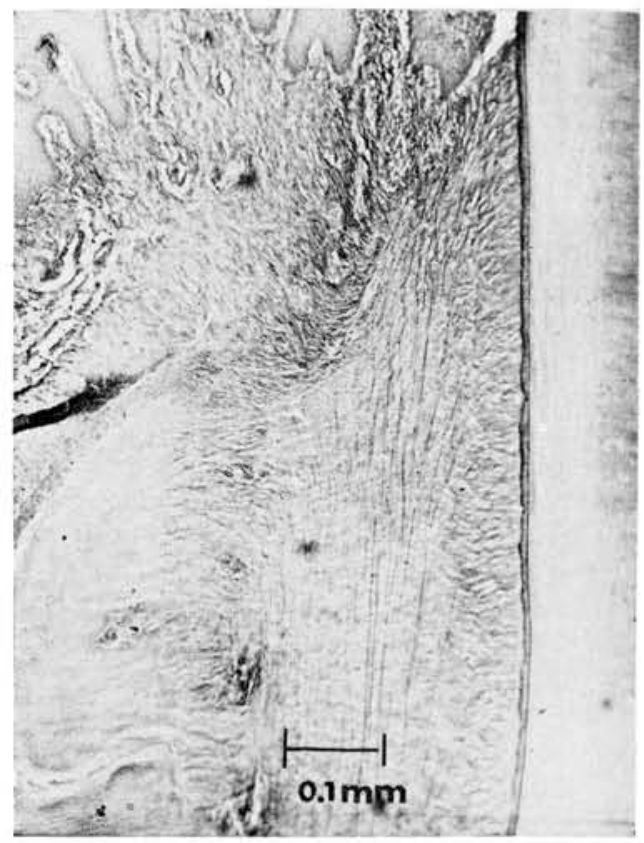

FIG. 2.-Photomicrograph of the maxillary incisor region of the normal guinea pig $(1.25 \mathrm{mg}$. of ascorbic acid per $100 \mathrm{Gm}$. of body weight). Oxytalan fibers may be seen in association with the alveolar crest group of collagenous fibers, bone, and cementum. The oxytalan fibers that run in an apicalocclusal direction are also apparent. (Peraceticaldehyde fuchsin; orig. mag. $\times 70$ )

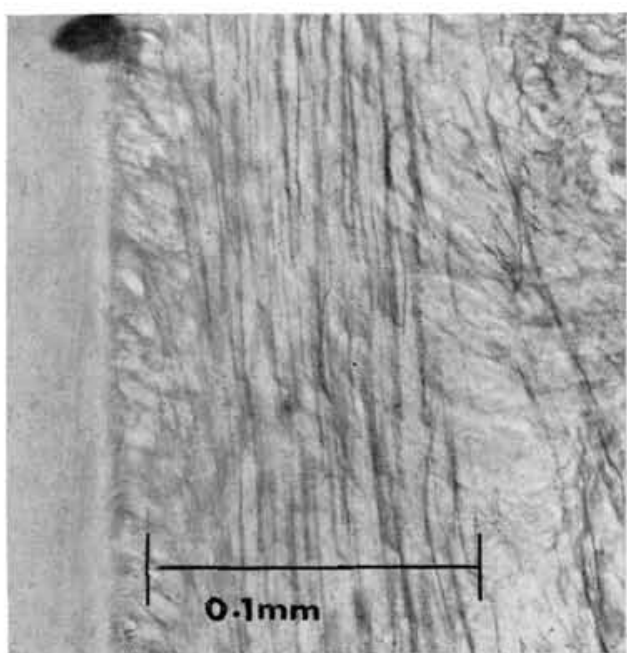

Fig. 3.- Photomicrograph at the level of the alveolar crest of the maxillary incisor at an ascorbic acid intake level of $0.2 \mathrm{mg}$. per $100 \mathrm{Gm}$. of body weight. The oxytalan fibers may be seen running in an apical-occlusal direction and attaching to cementum. (Peracetic-aldehyde fuchsin; orig. mag. $\times 300$.)

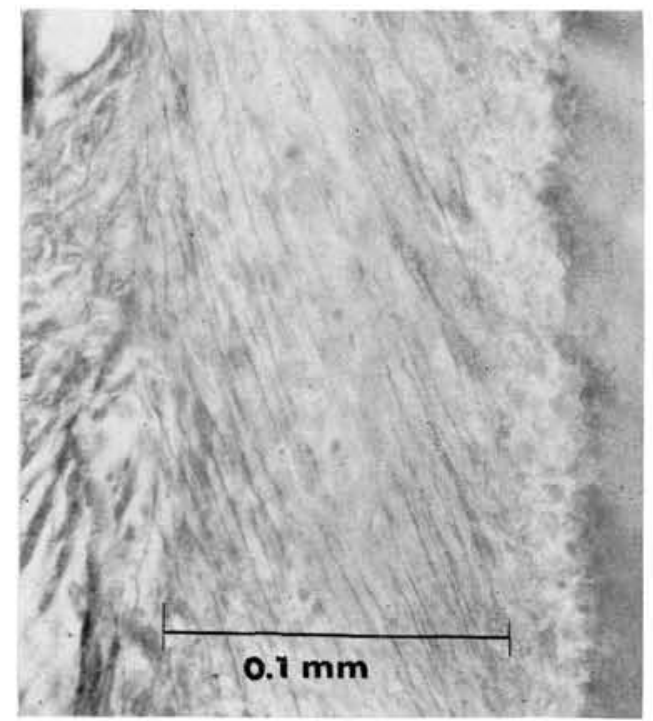

Fig. 4.-Photomicrograph at the alveolar crest area of the maxillary incisor in a scorbutic guinea pig. The oxytalan fibers may be seen running in an apical-occlusalidirection. (Peracetic-aldehyde fuchsin; orig. mag. $\times 300$.) 
per $100 \mathrm{Gm}$. of body weight, the guinea pigs revealed oxytalan fibers inferior to the root apexes, running in an apical occlusal direction in the center of the periodontal membrane. Other, often shorter, oxytalan fibers were attached to the alveolar bone, cementum, and cemental pearls. These periodontal membrane fibers did not run continuously from tooth to bone; they anastomosed with each other and followed the course of the major collagenous fiber bundles. The oxytalan fibers most often appeared interspersed between the groups of alveolar crest, free gingival, and transseptal collagenous fibers. A concentration of oxytalan fibers appeared in close proximity to the apical end of the epithelial attachment. The interstitial spaces in the periodontal membrane also contained these fibers. They were observed in the adventitia of blood vessels and in a peripheral arrangement in the interstitial spaces. Oxytalan fibers were also observed within the marrow spaces of the alveolar processes.

ASCORBIC ACID-DEFICIENT ANIMALS.-In the guinea pigs that received $0.8 \mathrm{mg}$. of ascorbic acid per $100 \mathrm{Gm}$. of body weight, no deviation from the normal distribution of oxytalan fibers was noted.

As the deficiency state of the guinea pigs increased, from 0.6 down to $0.0 \mathrm{mg}$. of ascorbic acid, they developed acute scurvy. The oxytalan fibers appeared more prominent in the sections. They were most

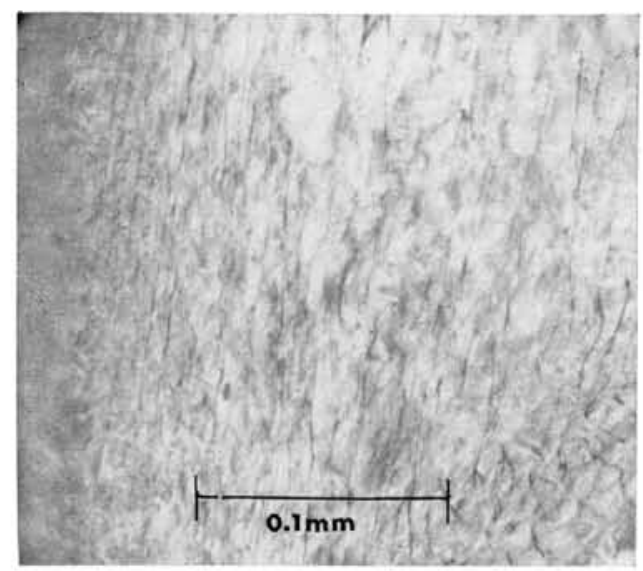

FIg. 5.-Photomicrograph at the alveolar crest area of the maxillary incisor in a scorbutic guinea pig, demonstrating the tendency for oxytalan fibers to persist in the face of severe collagen depletion. (Peracetic-aldehyde fuchsin; orig. mag. $\times 300$.)
TABLE 1

AVERAge NUMBER OF OXYTALAN FibERS AS COMPARED TO DAILY ASCORBIC ACID INTAKE

\begin{tabular}{ccc}
\hline \hline & \multicolumn{2}{c}{$\begin{array}{c}\text { Average Number of } \\
\text { Oxytalan Fibers }\end{array}$} \\
\cline { 2 - 3 } $\begin{array}{c}\text { DAily Ascorbic } \\
\text { ACID Litake }\end{array}$ & Area I & Area II \\
\hline 1.25 & 10.0 & 10.4 \\
0.80 & 9.7 & 8.0 \\
0.60 & 8.0 & 1.91 \\
0.40 & 9.5 & 9.0 \\
0.20 & 12.7 & 11.0 \\
0.00 & 11.2 & 10.5 \\
& & \\
\hline
\end{tabular}

noticeable in the region apical to the epithelial attachment, around the apex of the developing roots of the molar teeth, in association with the alveolar crest group of fibers, in the interstitial space region, and in the central portion of the periodontal membrane where the oxytalan fibers run in an apical occlusal direction (Fig. 3-5).

As seen in Table 1, the average number of oxytalan fibers adjacent to the epithelial attachment (Fig. 1) and the oxytalan fibers in the central portion of the periodontal membrane (Fig. 2) did not significantly increase as the ascorbic acid deficiency became more severe.

\section{Discussion}

The oxytalan fibers of the periodontal membrane appeared to increase in number as the scorbutic state was approached. However, from counting the number of fibers (Table 1) present in Figure 1, Area I, and Figure 1, Area II, it seems that this increase is only apparent and due to an unmasking of the oxytalan fibers associated with loss of collagen. This would indicate that the decrease in functional capacity of the periodontal membrane due to loss of collagen secondary to ascorbic acid deficiency does not lead to an increase in the number of oxytalan fibers. The individual oxytalan fibers appear to increase in size as the deficiency becomes more pronounced. It is difficult to determine whether this is a true increase in size or possibly again is apparent increase due to loss of collagenous tissue.

The demonstration of a histochemical difference between collagenous and oxytalan 
fibers on the basis of ascorbic acid deficiency does not rule out the possibility that the oxytalan fiber may be a precursor to the mature collagenous fiber, since collagen precursors are not necessarily affected by scurvy.

\section{Summary}

The periodontal membranes of Hartley strain guinea pigs were subjected to a range of ascorbic acid deficiencies for 30 days. Selective histochemical staining technics revealed a difference between the collagenous and oxytalan fibers. Quantitative differences between the normal and ascorbic acid-deficient oxytalan fiber component were evaluated by counting the number of oxytalan fibers in two areas of the incisor region. It was found that the collagenous fibers of the periodontal membrane decreased in number with the severity of the ascorbic acid deficiency and the oxytalan fibers remained unchanged in number and distribution.

The oxytalan fibers in the periodontal membrane of the guinea pig were not af- fected by ascorbic acid deficiency, indicating that these fibers are not collagen.

\section{References}

1. Fullmer, H. M., and Lillie, R. D. The Oxytalan Fiber: A Previously Undescribed Connective Tissue Fiber. J. Histochem. \& Cytochem., 6:425-30, 1959.

2. Fullmer, H. M. The Peracetic-Orcein-Halmi Stain: A Stain for Connective Tissue, Stain Tech., 34:81-84, 1959.

3. the Periodontium and Some Alterations with Periodontal Disease, $J$. deni. Res., 41:223-29, 1962.

4. - - A Comparative Histochemical Study of Elastic, Preelastic, and Oxytalan Connective Tissue Fibers, $J$. Histochem. and Cytochem., 8:290-95, 1960.

5. . Differential Staining of P. 8. Fibers in Areas of Stress, Science, 127:1240, 1958.

6. - Observations on the Development of Oxytalan Fibers in the Periodontium of Man, $J$. dent. Res., 38:510-18, 1959.

7. - Observations on the Development of Oxytalan Fibers in Dental Granulomas and Radicular Cysts, Arch. Path., 70:59-67, 1960.

8. . A Histochemical Study of Periodontal Disease in the Maxillary Alveolar Processes of 135 Autopsies, $J$. Periodont, 32:206-18, 1961.

9. REID, M. E., and BrIGGs, G. M. Development of a Semi-Synthetic Diet for Young Guinea Pigs, $J$. Nutr. 51:341-54, 1953.

10. RoE, J. H., and KeUther, C. A. The Determination of Ascorbic Acid in Whole Blood and Urine through the 24-Dinitrophenyl Hydrazine Derivative of Dehydroascorbic Acid, $f$. Biol. Chem., 147:399-407, 1943. 